\title{
Safety and efficacy of the Pipeline embolization device for treatment of intracranial aneurysms: a pooled analysis of 3 large studies
}

\author{
David F. Kallmes, MD, Waleed Brinjikji, MD, ${ }^{1}$ Saruhan Cekirge, MD, ${ }^{2}$ David Fiorella, MD, PhD, ${ }^{3}$ \\ Ricardo A. Hanel, MD, PhD, ${ }^{4}$ Pascal Jabbour, MD, ${ }^{5}$ Demetrius Lopes, MD, ${ }^{6}$ Pedro Lylyk, MD, ${ }^{7}$ \\ Cameron G. McDougall, MD, FRCSC, ${ }^{8}$ and Adnan Siddiqui, MD, $\mathrm{PhD}^{9}$
}

'Department of Radiology, Mayo Clinic, Rochester, Minnesota; ${ }^{3}$ Department of Neurosurgery, Cerebrovascular Center, Stony Brook University Medical Center, Stony Brook; ${ }^{\circ}$ Department of Neurosurgery, University at Buffalo Neurosurgery, Buffalo, New York; ${ }^{4}$ Stroke and Cerebrovascular Surgery, Lyerly Neurosurgery/Baptist Neurological Institute, Jacksonville, Florida; ${ }^{5}$ Department of Neurosurgery, Thomas Jefferson University, Philadelphia, Pennsylvania; ${ }^{6}$ Department of Neurological Surgery, Rush University Medical Center, Chicago, Illinois; ${ }^{8}$ Department of Endovascular Neurosurgery, Barrow Neurological Institute, Phoenix, Arizona; ${ }^{2}$ Koru Hospital and Bayindir Hospitals, Ankara, Turkey; and 'Department of Neurosurgery, ENERI-Clinica La Sagrada Familia, Buenos Aires, Argentina

OBJECTIVE The authors performed a pooled analysis of 3 studies-IntrePED (International Retrospective Study of the Pipeline Embolization Device), PUFS (Pipeline for Uncoilable or Failed Aneurysms Study), and ASPIRe (Aneurysm Study of Pipeline in an Observational Registry)-in order to assess angiographic outcomes and clinical safety of the Pipeline embolization device (PED).

METHODS IntrePED was a retrospective study, while PUFS and ASPIRe were prospective studies. For each patient included in these studies, the authors collected baseline demographic data, aneurysm characteristics, and procedural details. The primary outcomes for this combined analysis were clinical outcomes, including neurological morbidity and mortality and major ipsilateral intracranial hemorrhage and ischemic stroke. The secondary outcomes were angiographic occlusion rates, which were available for ASPIRe and PUFS only.

RESULTS A total of 1092 patients with 1221 aneurysms were included across the 3 studies. The mean aneurysm size was $12.0 \pm 7.8 \mathrm{~mm}$ and the mean neck size was $6.6 \pm 4.8 \mathrm{~mm}$. The major ipsilateral ischemic stroke rate was $3.7 \%$ (40/1091). The major ipsilateral intracranial hemorrhage rate was $2.0 \%$ (22/1091). The major neurological morbidity rate was $5.7 \%$ (62/1091). The neurological mortality rate was 3.3\% (36/1091). The combined major morbidity and neurological mortality rate was $7.1 \%(78 / 1091)$. The complete occlusion rates were $75.0 \%$ at 180 days $(111 / 148)$ and $85.5 \%$ at 1 year (94/110). The overall aneurysm retreatment rate was 3.0\% (33/1091) at a mean follow-up time of $10.2 \pm 10.8$ months.

CONCLUSIONS Endovascular treatment of intracranial aneurysms with the PED is safe and effective. Angiographic occlusion rates progressed with follow-up. Rates of stroke, hemorrhage, morbidity and mortality, and retreatment were low, especially given the fact that the aneurysms treated were generally large and wide necked.

https://thejns.org/doi/abs/10.3171/2016.8.JNS16467

KEY WORDS aneurysm; endovascular; stroke; vascular disorders; interventional neurosurgery

$\mathrm{T}$ REATMENT with the Pipeline embolization device (PED, Covidien/Medtronic) is widely accepted as an excellent option for patients with intracranial aneurysms. ${ }^{1,4,5,19}$ Flow diverter devices such as the PED were initially developed for treatment of wide-necked and large and giant aneurysms, aneurysms that are typically difficult to treat with endosaccular coiling, with or without stent assistance. High rates of complete aneurysm occlusion have been reported in a number of studies, even in large and giant aneurysms. ${ }^{1,4,5,7,8,17,19}$

ABBREVIATIONS ASPIRe = Aneurysm Study of Pipeline in an Observational Registry; ICA = internal carotid artery; IntrePED = International Retrospective Study of the Pipeline Embolization Device; IQR = interquartile range; PED = Pipeline embolization device; PUFS = Pipeline for Uncoilable or Failed Aneurysms Study.

SUBMITTED February 23, 2016. ACCEPTED August 3, 2016.

INCLUDE WHEN CITING Published online October 28, 2016; DOI: 10.3171/2016.8.JNS16467. 
TABLE 1. Patient characteristics

\begin{tabular}{|c|c|c|c|c|}
\hline Characteristic & PUFS & IntrePED & ASPIRe & Total \\
\hline \multicolumn{5}{|l|}{ Age, yrs } \\
\hline Mean $\pm \mathrm{SD}(\mathrm{N})$ & $57.0 \pm 11.3(108)$ & $56.9 \pm 14.2(789)$ & $59.9 \pm 12.5(191)$ & $57.4 \pm 13.7(1088)$ \\
\hline Median & 59.0 & 58.0 & 60.0 & 58.0 \\
\hline Range & $30.2-75.0$ & $3.0-86.0$ & $25.0-89.0$ & $3.0-89.0$ \\
\hline \multicolumn{5}{|l|}{ Sex } \\
\hline Male & $11.1 \%(12 / 108)$ & $20.3 \%(161 / 793)$ & $16.2 \%(31 / 191)$ & $18.7 \%(204 / 1092)$ \\
\hline Female & $88.9 \%(96 / 108)$ & $79.7 \%(632 / 793)$ & $83.8 \%(160 / 191)$ & $81.3 \%(888 / 1092)$ \\
\hline \multicolumn{5}{|l|}{ Procedure time, mins } \\
\hline Mean \pm SD $(\mathrm{N})$ & $121.8 \pm 62.6(108)$ & $101.6 \pm 50.5(754)$ & $112.9 \pm 54.9(190)$ & $105.7 \pm 53.1(1052)$ \\
\hline Median & 109.5 & 90.0 & 107.0 & 92.0 \\
\hline Range & $39.0-427.0$ & $10.0-376.0$ & $0.0-369.0$ & $0.0-427.0$ \\
\hline \multicolumn{5}{|l|}{ Clinical follow-up, days } \\
\hline Mean \pm SD $(\mathrm{N})$ & $1540.8 \pm 639.0(108)$ & $667.4 \pm 268.1(793)$ & $200.4 \pm 169.7(191)$ & $672.1 \pm 459.3(1092)$ \\
\hline Median & 1841 & 637.0 & 188.0 & 604.5 \\
\hline Range & 0-2051 & 2-1839 & $0-826$ & $0-2051$ \\
\hline \multicolumn{5}{|c|}{ Angiographic follow-up, mos } \\
\hline Mean \pm SD (N) & $50.0 \pm 16.9(101)$ & - & $9.2 \pm 4.3(115)$ & $28.3 \pm 23.7(216)$ \\
\hline Median & 60.1 & - & 7.6 & 14.1 \\
\hline Range & $6.6-67.5$ & - & $3.6-27.2$ & $3.6-67.5$ \\
\hline
\end{tabular}

To date, a majority of previously published studies are small single-institution case series, and their results may not be generalizable to the overall patient population. IntrePED (International Retrospective Study of the Pipeline Embolization Device), PUFS (Pipeline for Uncoilable or Failed Aneurysms Study), and ASPIRe (Aneurysm Study of Pipeline in an Observational Registry) represent large, multicenter studies that followed predefined protocols to fully characterize the safety and efficacy of the PED. These studies include a broad range of aneurysm types, locations, and sizes and represent the experience of a wide number of practitioners. In this study, we present a pooled analysis of patients included in these studies to better evaluate both clinical safety and angiographic outcomes of PED treatment.

\section{Methods}

\section{Patient Population}

All centers included in these 3 studies acquired institutional review board or ethics committee approval for the studies. All patients included in PUFS (NCT00777088), ${ }^{2}$ IntrePED,${ }^{10}$ and ASPIRe (NCT01557036) were included in this combined analysis. PUFS was a prospective single-arm clinical trial involving 108 patients with 108 aneurysms; it included only patients with wide-necked $(\geq 4$ $\mathrm{mm}$ ) aneurysms or aneurysms with no discernable neck and large (10-24.9 $\mathrm{mm}$ ) or giant ( $\geq 25 \mathrm{~mm}$ ) aneurysms of the internal carotid artery (ICA) from the petrous to the superior hypophyseal segments with a follow-up time of 5 years. IntrePED was a retrospective postmarket registry of 793 patients with 906 aneurysms, including both ruptured and unruptured aneurysms (no size or location criteria) with a follow-up time of up to 3 years. The IntrePED study did not include angiographic outcomes as it was designed to assess safety-related outcomes only. ASPIRe was a prospective postmarket registry involving 191 patients with 207 aneurysms with a follow-up time of up to 2 years; size and location inclusion criteria for ASPIRe followed the country-specific PED instructions for use.

We pooled data from these 3 studies including patients with unruptured and ruptured aneurysms. Data on the following baseline characteristics were collected and analyzed: age, sex, aneurysm size, aneurysm neck size, aneurysm type (saccular, fusiform, dissecting, other), aneurysm location, and aneurysm rupture status (Tables 1 and 2).

\section{Outcomes}

The primary outcomes of this study were complication rates. Complications studied included major ipsilateral ischemic stroke, major ipsilateral intracranial hemorrhage, major neurological morbidity, neurological mortality, combined major neurological morbidity and mortality and all-cause mortality. In PUFS, a major stroke or other neurological event was defined as a stroke with symptoms present after 7 days of the initial event with an increase in the NIH stroke scale by at least 4 points. In IntrePED and ASPIRe, a major neurological event (stroke, hemorrhage, or morbidity) was defined as an ongoing clinical deficit at 7 days following the event. For angiographic outcomes, data were available from ASPIRe and PUFS only. In the IntrePED registry, images were not collected and imaging was not a prespecified outcome. All adverse events were adjudicated by an independent adverse events committee that was completely independent of the funding source.

The secondary outcomes were angiographic results 
TABLE 2. Aneurysm characteristics

\begin{tabular}{|c|c|c|c|c|}
\hline Characteristic & PUFS & IntrePED & ASPIRe & Total \\
\hline No. of aneurysms & 108 & 906 & 207 & 1221 \\
\hline No. of patients & 108 & 793 & 191 & 1092 \\
\hline \multicolumn{5}{|l|}{ Aneurysm size, $\mathrm{mm}$} \\
\hline Mean \pm SD (N) & $18.2 \pm 6.5(108)$ & $10.7 \pm 7.7(896)$ & $14.5 \pm 6.9(207)$ & $12.0 \pm 7.8(1211)$ \\
\hline Median & 17.5 & 9.0 & 12.0 & 10.2 \\
\hline Range & $6.2-36.1$ & $1.0-55.0$ & $0.9-41.0$ & $0.9-55.0$ \\
\hline \multicolumn{5}{|l|}{ Aneurysm neck, mm } \\
\hline Mean \pm SD (N) & $8.8 \pm 4.3(108)$ & $6.2 \pm 4.9(812)$ & $7.1 \pm 4.2(202)$ & $6.6 \pm 4.8(1122)$ \\
\hline Median & 8.1 & 5.0 & 6.0 & 5.4 \\
\hline Range & $4.1-36.1$ & $0.8-53.0$ & $0.0-32.0$ & $0.0-53.0$ \\
\hline \multicolumn{5}{|l|}{ Aneurysm location, \% (n/N) } \\
\hline ICA/PCoA & $100.0 \%(108 / 108)$ & $82.3 \%(746 / 906)$ & $90.8 \%(188 / 207)$ & $85.3 \%(1042 / 1221)$ \\
\hline ICA & $100.0 \%(108 / 108)$ & $91.8 \%(685 / 746)$ & $98.4 \%(185 / 188)$ & $93.9 \%(978 / 1042)$ \\
\hline PCoA & $0.0 \%(0 / 108)$ & $8.2 \%(61 / 746)$ & $1.6 \%(3 / 188)$ & $6.1 \%(64 / 1042)$ \\
\hline MCA & $0.0 \%(0 / 108)$ & $4.9 \%(44 / 906)$ & $1.4 \%(3 / 207)$ & $3.8 \%(47 / 1221)$ \\
\hline PCA & $0.0 \%(0 / 108)$ & $1.7 \%(15 / 906)$ & $0.5 \%(1 / 207)$ & $1.3 \%(16 / 1221)$ \\
\hline $\mathrm{BA}$ & $0.0 \%(0 / 108)$ & $4.9 \%(44 / 906)$ & $2.9 \%(6 / 207)$ & $4.1 \%(50 / 1221)$ \\
\hline ACoA/ACA & $0.0 \%(0 / 108)$ & $2.3 \%(21 / 906)$ & $2.9 \%(6 / 207)$ & $2.2 \%(27 / 1221)$ \\
\hline ACoA & $0.0 \%(0 / 108)$ & $57.1 \%(12 / 21)$ & $83.3 \%(5 / 6)$ & $63.0 \%(17 / 27)$ \\
\hline ACA & $0.0 \%(0 / 108)$ & $42.9 \%(9 / 21)$ & $16.7 \%(1 / 6)$ & $37.0 \%(10 / 27)$ \\
\hline VA & $0.0 \%(0 / 108)$ & $3.6 \%(33 / 906)$ & $1.4 \%(3 / 207)$ & $2.9 \%(36 / 1221)$ \\
\hline PICA & $0.0 \%(0 / 108)$ & $0.3 \%(3 / 906)$ & $0.0 \%(0 / 207)$ & $0.2 \%(3 / 1221)$ \\
\hline Ruptured aneurysms, \% (n/N) & $0.0 \%(0 / 108)$ & $8.4 \%(76 / 906)$ & $0.0 \%(0 / 207)$ & $6.2 \%(76 / 1221)$ \\
\hline Multiple PEDs used, \% (n/N) & $98.1 \%(105 / 107)$ & $34.1 \%(308 / 904)$ & $18.8 \%(39 / 207)$ & $37.1 \%(452 / 1218)$ \\
\hline
\end{tabular}

$\mathrm{ACA}=$ anterior cerebral artery; $\mathrm{ACOA}=$ anterior communicating artery; $\mathrm{BA}=$ basilar artery; $\mathrm{ICA}=$ internal carotid artery; $\mathrm{MCA}=$ middle cerebral artery; $\mathrm{PCA}=$ posterior cerebral artery; $\mathrm{PCOA}=$ posterior communicating artery; $\mathrm{PICA}=$ posterior inferior cerebellar artery; $\mathrm{VA}=$ vertebral artery.

following PED treatment. For angiographic outcomes, data were available from ASPIRe and PUFS only. Angiographic follow-up was available at 180 days and 1 year for ASPIRe and PUFS and at 3 and 5 years for PUFS only. All angiographic outcomes were adjudicated by a core laboratory using the Raymond-Roy occlusion scale. The core laboratory was completely independent of the funding source. In addition to clinical and angiographic outcomes, mean procedure time was reported.

\section{Statistical Analysis}

Statistical analyses were performed using SAS version 9.2 (SAS Institute Inc.). Summary statistics are presented for all data available using means and standard deviations for continuous variables and frequency tabulations for categorical variables. Most statistical analyses were performed on a per-patient basis. Some patients had more than 1 aneurysm treated with a PED. In these patients, the largest aneurysm was used to classify patients into the 3 aneurysm size categories. Some analyses, including aneurysm characteristics and multiple PED use, were performed across all aneurysms rather than across patients.

\section{Role of the Funding Source}

For all 3 studies, an academic principal investigator and an academic steering committee supervised trial design and operations. The principal investigators and steering committees were independent of the funding source. The steering committees interpreted the results. The 2 lead authors of this paper (D.F.K. and W.B.) drafted the initial manuscript and the remaining authors critically revised it. The study sponsor did not play a role in manuscript preparation. The study sponsor was responsible for site management, data management, statistical analysis, and safety reporting. The corresponding author had full access to all study data and had final responsibility for the decision to submit for publication.

\section{Results \\ Baseline Characteristics}

A total of 1092 patients with 1221 aneurysms were included in this study (Tables 1 and 2). There were 108 patients with 108 aneurysms enrolled in PUFS, 793 patients with 906 aneurysms were enrolled in IntrePED, and 191 patients with 207 aneurysms were enrolled in ASPIRe. In the combined patient population, $81.3 \%$ of patients (888/1092) were female and $18.7 \%$ of patients (204/1092) were male. The patients' mean age was 57.4 \pm 13.7 years. Overall, the mean aneurysm size was 12.0 $\pm 7.8 \mathrm{~mm}$ and the mean aneurysm neck size was $6.6 \pm$ $4.8 \mathrm{~mm}$. For PUFS, the mean aneurysm size was $18.2 \pm$ 
TABLE 3. Clinical outcomes: major complications

\begin{tabular}{lllll}
\hline \multicolumn{1}{c}{ Complication } & PUFS (n/N) & IntrePED (n/N) & ASPIRe $(\mathrm{n} / \mathrm{N})$ & Total $(\mathrm{n} / \mathrm{N})$ \\
\hline Major ipsilateral ischemic stroke & $2.8 \%(3 / 107)$ & $4.3 \%(34 / 793)$ & $1.6 \%(3 / 191)$ & $3.7 \%(40 / 1091)$ \\
\hline Major ipsilateral intracranial hemorrhage & $1.9 \%(2 / 107)$ & $1.8 \%(14 / 793)$ & $3.1 \%(6 / 191)$ & $2.0 \%(22 / 1091)$ \\
\hline Major morbidity & $4.7 \%(5 / 107)$ & $6.1 \%(48 / 793)$ & $4.7 \%(9 / 191)$ & $5.7 \%(62 / 1091)$ \\
\hline Neurological mortality & $2.8 \%(3 / 107)$ & $3.8 \%(30 / 793)$ & $1.6 \%(3 / 191)$ & $3.3 \%(36 / 1091)$ \\
\hline Major morbidity \& neurological mortality & $5.6 \%(6 / 107)$ & $7.7 \%(61 / 793)$ & $5.8 \%(11 / 191)$ & $7.1 \%(78 / 1091)$ \\
\hline All-cause mortality & $3.7 \%(4 / 107)$ & $4.2 \%(33 / 793)$ & $3.7 \%(7 / 191)$ & $4.0 \%(44 / 1091)$ \\
\hline
\end{tabular}

$6.5 \mathrm{~mm}$ and the median size was $17.5 \mathrm{~mm}$ (interquartile range [IQR] 11.8-23.3 mm). For IntrePED, the mean aneurysm size was $10.7 \pm 7.7 \mathrm{~mm}$ and median size was 9.0 $\mathrm{mm}$ (IQR 5.0-15.0 mm). For ASPIRe, the mean aneurysm size was $14.5 \pm 6.9 \mathrm{~mm}$ and the median size was $12.0 \mathrm{~mm}$ (IQR 10.0-18.9 mm). At baseline, $6.2 \%$ of aneurysms (76/1221) were ruptured. Multiple PEDs were used in $37.1 \%$ of cases $(452 / 1218)$. The mean procedure time was $105.7 \pm 53.1$ minutes. A majority of aneurysms $(93.9 \%$, $1042 / 1221)$ were located in the ICA. There were 64 aneurysms $(6.1 \%, 64 / 1042)$ in the posterior communicating artery, 47 aneurysms $(3.8 \%, 47 / 1221)$ in the middle cerebral artery, 50 aneurysms $(4.1 \%, 50 / 1221)$ in the basilar artery, 27 aneurysms in the anterior communicating artery or anterior cerebral artery $(2.2 \%, 27 / 1221), 36$ aneurysms in the vertebral artery $(2.9 \%, 36 / 1221)$, and 3 aneurysms in the posterior inferior cerebellar artery $(0.2 \%, 3 / 1221)$.

\section{Complications}

Complication data were available for 1091 patients (Table 3). The overall rate of major ipsilateral ischemic stroke was 3.7\% (40/1091). Major ipsilateral intracranial hemorrhage occurred in $2.0 \%$ of cases $(22 / 1091)$. Major neurological morbidity occurred in $5.7 \%$ of cases (62/1091). Neurological mortality occurred in $3.3 \%$ of cases (36/1091). Combined major neurological morbidity and mortality occurred in $7.1 \%$ of cases (78/1091). The allcause mortality rate was $4.0 \%$ (44/1091).

\section{Angiographic Outcomes}

Angiographic outcomes were available at 180 days and 12 months for both ASPIRe and PUFS and at 3 and 5 years for PUFS only (Table 4). The sizes of the aneurysms at each time point are summarized in Table 5. The mean length of angiographic follow-up was $28.3 \pm 23.7$ months. Complete occlusion rates were $75.0 \%(111 / 148)$, $85.5 \%$ (94/110), 93.4\% (71/76), and 95.2\% (59/62) at 180 days and 1,3 , and 5 years, respectively. Overall aneurysm retreatment rates were low at $3.0 \%$ (33/1091) at a mean follow-up time of $10.2 \pm 10.8$ months. IntrePED had the lowest reported retreatment rate-1.9\% (15/793) at a mean follow-up time of $6.6 \pm 6.1$ months. Retreatment rates for PUFs and ASPIRe were similar-6.5\% (7/107) at a mean follow-up time of $24.5 \pm 12.2$ months and $5.8 \%(11 / 191)$ at a mean follow-up time of $6.1 \pm 7.3$ months, respectively.

\section{Discussion}

Our study of 1092 patients with 1221 aneurysms demonstrates that flow diversion treatment of intracranial aneurysms is safe and effective. Complete occlusion rates were over $85 \%$ at 1 year and over $95 \%$ at 5 years. In addition, the rates of stroke, hemorrhage, morbidity, and mortality were low, especially given the fact that treated aneurysms were generally large and wide necked and included both ruptured and unruptured lesions. While a number of studies and meta-analyses have been published regarding the outcomes of flow diverter treatment of intracranial aneurysms, the current study is the largest study with individual patient data to date. In addition, all clinical outcomes were adjudicated by an independent clinical events committee, and all angiographic outcomes were validated by an independent core laboratory.

Our findings corroborate the findings of many recently published meta-analyses on the safety and efficacy of flow diverter treatment of intracranial aneurysms. Two recently published large meta-analyses of flow diverter treatment demonstrated morbidity and mortality rates of 5\%-7\% and $3 \%-4 \%$, respectively. ${ }^{1,3}$ Meanwhile, our combined analysis with adjudicated clinical outcomes found major morbidity and neurological mortality rates of $5.7 \%$ and $3.3 \%$, respectively.

Prior studies have demonstrated high angiographic cure rates when treating large aneurysms with flow diverters such as the PED. In general, complete occlusion rates at 6-12 months range between $70 \%$ and $85 \% .^{2,11,12,14,15,18}$ Such studies corroborate our findings that the rates of complete

TABLE 4. Angiographic outcomes: complete aneurysm occlusion

\begin{tabular}{llccc}
\hline \multicolumn{1}{c}{ Follow-Up } & PUFS $(\mathrm{n} / \mathrm{N})$ & IntrePED $(\mathrm{n} / \mathrm{N})$ & ASPIRe $(\mathrm{n} / \mathrm{N})$ & Total $(\mathrm{n} / \mathrm{N})$ \\
\hline 180 days (-20/+42 days) & $73.6 \%(78 / 106)$ & - & $78.6 \%(33 / 42)$ & $75.0 \%(111 / 148)$ \\
\hline 1 yr $( \pm 42$ days $)$ & $86.8 \%(79 / 91)$ & - & $78.9 \%(15 / 19)$ & $85.5 \%(94 / 110)$ \\
\hline 3 yrs & $93.4 \%(71 / 76)$ & - & - & $93.4 \%(71 / 76)$ \\
\hline 5 yrs & $95.2 \%(59 / 62)$ & - & - & $95.2 \%(59 / 62)$ \\
\hline
\end{tabular}


TABLE 5. Summary of aneurysm sizes and each follow-up period for angiographic outcomes

\begin{tabular}{lccccc}
\hline $\begin{array}{c}\text { Aneurysm } \\
\text { Size }\end{array}$ & $\begin{array}{c}\text { 180-Day Angio } \\
\text { FU for PUFS }\end{array}$ & $\begin{array}{c}\text { 1-Yr Angio FU } \\
\text { for PUFS }\end{array}$ & $\begin{array}{c}\text { 3-Yr Angio FU } \\
\text { for PUFS }\end{array}$ & $\begin{array}{c}\text { 5-Yr Angio FU } \\
\text { for PUFS }\end{array}$ & $\begin{array}{c}\text { Last Angio FU Visit } \\
\text { for ASPIRe Patients }\end{array}$ \\
\hline Mean, $\mathrm{mm}^{*}$ & $18.3 \pm 6.4(106)$ & $18.4 \pm 6.5(91)$ & $17.9 \pm 6.2(76)$ & $18.4 \pm 6.9(62)$ & $14.2 \pm 6.2(126)$ \\
\hline Median, mm & 17.8 & 18.0 & 17.2 & 18.3 & 12.0 \\
\hline IQR, $\mathrm{mm}$ & $12.2-23.5$ & $12.0-24.2$ & $11.9-22.5$ & $11.5-24.0$ & $10.0-17.1$ \\
\hline $\begin{array}{l}\text { Angio }=\text { angiographic; FU = follow-up. } \\
\text { * Values in parentheses are numbers of aneurysms. }\end{array}$
\end{tabular}

occlusion at 6 and 12 months were $75 \%$ and $85 \%$, respectively. One meta-analysis of nearly 1500 patients with 1700 aneurysms treated with flow diverters demonstrated complete occlusion rates of $76 \%$ at last follow-up. ${ }^{3}$ Most studies in this meta-analysis had a maximum follow-up of 6-12 months. Series reporting angiographic outcomes at more than 1 year after treatment generally report complete occlusion rates of over $90 \%$, similar to our study. ${ }^{3,16}$ It is important to note that 3-and 5-year angiographic outcome data were only collected in PUFS.

When comparing angiographic and clinical outcomes of PED treatment of wide-necked and large aneurysms to reported outcomes of stent-assisted coiling and coiling alone, it appears as though PED treatment results in higher rates of angiographic occlusion with similar rates of morbidity and mortality. This is especially important in the context of the challenges associated with repeated treatments over time with conventional endovascular techniques resulting in poorly defined cumulative morbidity. ${ }^{6,13}$ In a series of over 150 large and giant ICA aneurysms treated with coil embolization, Chalouhi et al. noted a $12 \%$ complication rate with recurrence and retreatment rates greater than $30 \% .^{6}$ In our study, PED treatment resulted in low overall retreatment rates, with a mean of $3.0 \%$ at a mean follow-up of 10.2 months.

In a meta-analysis of over 2000 cases of wide-necked aneurysms treated with coiling and stent-assisted coiling, Zhao et al. found long-term complete occlusion rates of $70 \%-80 \%$ with recanalization rates of about $10 \% .20$ The long-term rate of good neurological outcome was approximately $90 \%$ for both groups, and procedure-related complications resulting in morbidity or mortality occurred in approximately $3 \%$ of patients. Other large studies have demonstrated mortality rates ranging from $3 \%$ to $9 \%$ and permanent morbidity rates ranging from $4 \%$ to $6 \%$ following stent-assisted coiling of intracranial aneurysms. ${ }^{9}$

\section{Limitations}

Our study has limitations. Most of the patients included in this combined analysis were included in either a prospective study (PUFS), a prospective postmarket registry (ASPIRe), or a retrospective registry (IntrePED). Because of this, there was no overall standardization in the perioperative management, including the use of platelet testing. In most cases, sites followed their standard of practice for treating aneurysms with PED and there was a wide range of treatment regimens (i.e., platelet testing and antiplatelet therapy) between centers. However, all study adverse events collected were pre-specified and were evaluated by an independent clinical events committee to maintain consistency. Another potential limitation of this study is the fact that the indications for treatment varied between centers, which can result in a degree of selection bias. Angiographic outcomes were not available for a vast majority of patients included in this study. Three- and 5-year angiographic outcomes were only available for PUFS. Nonetheless, our study represents the largest study with individual patient data reporting clinical outcomes of patients treated with the PED to date.

\section{Conclusions}

Our combined analysis of 3 large studies of the PED in the treatment of intracranial aneurysms with a broad range of sizes and locations and ruptured status confirms that treatment of intracranial aneurysms with the PED is both safe and effective, with progressively increasing occlusion rates over time, low rates of neurological morbidity and mortality, and low retreatment rates in long-term follow-up. These findings should be considered when determining the best therapeutic option for intracranial aneurysms.

\section{References}

1. Arrese I, Sarabia R, Pintado R, Delgado-Rodriguez M: Flow-diverter devices for intracranial aneurysms: systematic review and meta-analysis. Neurosurgery 73:193-200, 2013

2. Becske T, Kallmes DF, Saatci I, McDougall CG, Szikora I, Lanzino G, et al: Pipeline for uncoilable or failed aneurysms: results from a multicenter clinical trial. Radiology 267:858868,2013

3. Briganti F, Napoli M, Leone G, Marseglia M, Mariniello G, Caranci F, et al: Treatment of intracranial aneurysms by flow diverter devices: long-term results from a single center. Eur J Radiol 83:1683-1690, 2014

4. Briganti F, Napoli M, Tortora F, Solari D, Bergui M, Boccardi $\mathrm{E}$, et al: Italian multicenter experience with flow-diverter devices for intracranial unruptured aneurysm treatment with periprocedural complications - a retrospective data analysis. Neuroradiology 54:1145-1152, 2012

5. Brinjikji W, Murad MH, Lanzino G, Cloft HJ, Kallmes DF: Endovascular treatment of intracranial aneurysms with flow diverters: a meta-analysis. Stroke 44:442-447, 2013

6. Chalouhi N, Tjoumakaris S, Gonzalez LF, Dumont AS, Starke RM, Hasan D, et al: Coiling of large and giant aneurysms: complications and long-term results of 334 cases. AJNR Am J Neuroradiol 35:546-552, 2014

7. Chan TT, Chan KY, Pang PK, Kwok JC: Pipeline embolisation device for wide-necked internal carotid artery aneurysms in a hospital in Hong Kong: preliminary experience. Hong Kong Med J 17:398-404, 2011 
8. Cirillo L, Dall'olio M, Princiotta C, Simonetti L, Stafa A, Toni F, et al: The use of flow-diverting stents in the treatment of giant cerebral aneurysms: preliminary results. Neuroradiol J 23:220-224, 2010

9. Hong Y, Wang YJ, Deng Z, Wu Q, Zhang JM: Stent-assisted coiling versus coiling in treatment of intracranial aneurysm: a systematic review and meta-analysis. PLoS One 9:e82311, 2014

10. Kallmes DF, Hanel R, Lopes D, Boccardi E, Bonafé A, Cekirge $S$, et al: International retrospective study of the pipeline embolization device: a multicenter aneurysm treatment study. AJNR Am J Neuroradiol 36:108-115, 2015

11. Lylyk P, Miranda C, Ceratto R, Ferrario A, Scrivano E, Luna $\mathrm{HR}$, et al: Curative endovascular reconstruction of cerebral aneurysms with the pipeline embolization device: the Buenos Aires experience. Neurosurgery 64:632-633, N636, 2009

12. Moon K, Albuquerque FC, Ducruet AF, Crowley RW, McDougall CG: Resolution of cranial neuropathies following treatment of intracranial aneurysms with the Pipeline Embolization Device. J Neurosurg 121:1085-1092, 2014

13. Morita A, Kirino T, Hashi K, Aoki N, Fukuhara S, Hashimoto N, et al: The natural course of unruptured cerebral aneurysms in a Japanese cohort. N Engl J Med 366:2474-2482, 2012

14. Nelson PK, Lylyk P, Szikora I, Wetzel SG, Wanke I, Fiorella $D$ : The pipeline embolization device for the intracranial treatment of aneurysms trial. AJNR Am J Neuroradiol 32:34-40, 2011

15. Puffer RC, Piano M, Lanzino G, Valvassori L, Kallmes DF, Quilici L, et al: Treatment of cavernous sinus aneurysms with flow diversion: results in 44 patients. AJNR Am J Neuroradiol 35:948-951, 2014

16. Saatci I, Yavuz K, Ozer C, Geyik S, Cekirge HS: Treatment of intracranial aneurysms using the pipeline flow-diverter embolization device: a single-center experience with longterm follow-up results. AJNR Am J Neuroradiol 33:14361446, 2012

17. Siddiqui AH, Kan P, Abla AA, Hopkins LN, Levy EI: Complications after treatment with pipeline embolization for giant distal intracranial aneurysms with or without coil embolization. Neurosurgery 71:E509-E513, 2012

18. Szikora I, Berentei Z, Kulcsar Z, Marosfoi M, Vajda ZS, Lee $\mathrm{W}$, et al: Treatment of intracranial aneurysms by functional reconstruction of the parent artery: the Budapest experience with the pipeline embolization device. AJNR Am J Neuroradiol 31:1139-1147, 2010

19. Yu SC, Kwok CK, Cheng PW, Chan KY, Lau SS, Lui WM, et al: Intracranial aneurysms: midterm outcome of pipeline embolization device-a prospective study in 143 patients with 178 aneurysms. Radiology 265:893-901, 2012

20. Zhao B, Yin R, Lanzino G, Kallmes DF, Cloft HJ, Brinjikji $\mathrm{W}$ : Endovascular coiling of wide-neck and wide-neck bifur- cation aneurysms: a systematic review and meta-analysis. AJNR Am J Neuroradiol 37:1700-1705, 2016

\section{Disclosures}

Funding for this study was provided by Medtronic. Dr. Kallmes reports receiving consulting fees and support for the present study from Medtronic. He also reports receiving support for non-study-related research of clinical efforts from MicroVention, Codman, NeuroSigma, Sequent Medical, and Surmodics. Dr. Fiorella reports a consultant relationship with Medtronic, Codman, Sequent, MicroVention, and Penumbra. Dr. Hanel reports receiving consulting fees and research funding from Medtronic; a consultant relationship with Codman, Stryker, and MicroVention; and direct stock ownership in Blockade. Dr. Jabbour reports a consultant relationship with Medtronic. Dr. Lopes reports receiving consulting fees and support for non-study-reated clinical or research efforts from Medtronic as well as being a principal investigator for PUFS, IntrePED, ASPIRe, and PREMIER. Dr. McDougall reports a consultant relationship with MicroVention and Covidien/Medtronic. Dr. Siddiqui reports receiving consulting fees from Medtronic and having a consultant relationship with Codman \& Shurtleff, Covidien, Guidepoint Global Consulting, Penumbra, Stryker, Pulsar Vascular, MicroVention, Lazarus Effect, Blockade Medical, Reverse Medical, WL Gore \& Associates, Three Rivers Medical, Corindus, Amnis Therapeutics, Ltd., and CereVasc, LLC; direct stock ownership in Hotspur, Intratech Medical, StimSox, Valor Medical, Blockade Medical, Lazarus Effect, Pulsar Vascular, Medina Medical, Inc., Three Rivers Medical, Inc., Amnis Therapeutics, Ltd., The Stroke Project, Inc., and Cerevatech Medical; being on national steering commttees for the Penumbra 3D Separator Trial, Covidien SWIFT PRIME Trial, and MicroVention CONFIDENCE and FRED Trials; and being on the advisory board of Codman \& Shurtleff, ICAVL, Medina Medical, Inc., Three Rivers Medical, Inc., Amnis Therapeutics, Ltd., The Stroke Project, Inc., CereVasc LLC, and Corindus, Inc.

\section{Author Contributions}

Conception and design: Brinjikji. Acquisition of data: Brinjikji. Analysis and interpretation of data: Brinjikji, Kallmes. Drafting the article: all authors. Critically revising the article: all authors. Reviewed submitted version of manuscript: Brinjikji, Cekirge, Fiorella, Hanel, Jabbour, Lopes, Lylyk, McDougall, Siddiqui. Approved the final version of the manuscript on behalf of all authors: Brinjikji. Statistical analysis: Brinjikji.

\section{Correspondence}

Waleed Brinjikji, Department of Radiology, Mayo Clinic, 200 1st St. SW, Rochester, MN 55905. email: brinjikji.waleed@mayo.edu. 